\title{
MJMR MILLENNIALS MAGNIFIED: A PHENOMENOLOGICAL APPROACH ON THE TEACHING AND LEARNING EXPERIENCES OF MILLENNIAL NURSING STUDENTS
}

\author{
Mariedith J. Maghari, Karl Bryant R. Munalim, Emilyn S. Nuez, Julius Colonia Daño* \\ Bachelor of Science in Nursing, Cebu Normal University, Philippines \\ *Corresponding Author’s Email: juliuscoloniadano@gmail.com
}

\begin{abstract}
Learning is unachievable in the absence of effective teaching. A paradigm shift is occurring as new generation of learners, the millennials enter into the college classroom. The study aims to explore the teaching and learning experiences of millennial nursing students. Husserlian Phenomenology was used to address the problems of the study. Phenomenological in nature, the study utilized an in-depth, semi-structured interview tool in data collection. Collaizi's seven-step method was used in analyzing the data. Data saturation was used in determining the sample size. Eleven informants were selected using the eligibility criteria. This includes nursing students in the Level IV regardless of sex, currently enrolled in the Bachelor of Science in Nursing Program in any prestigious university. The study generated six major themes: (1) "The Ticks of Time" which discusses experiences of managing time and pressure, (2) "The Art of the Advanced" referring to use of gadgets and online resources as means of knowledge reinforcement, (3) "The Pampered Pupil" referring to student-centric teaching approaches, (4) "The Paternalistic Professor" characterized by teacher-centric discussions and minimal student participation, (5) "The Stylish Learner" which presents how students enhance learning, and (6) "The Encounter with the Educator" which describes the attitudes of teachers towards students. Altogether, the study presented both positive and negative phenomena experienced by the millennial learners and is recommended to educators in administering effective learning through provision of essentially congruent and timely teaching strategies.
\end{abstract}

Keywords: Approach on Teaching, Learning Experiences, Millennials, Magnified

\section{INTRODUCTION}

\section{Background and Rationale}

According to R.M Smith, it has been suggested that the term "learning" is put to multiple uses. It is referred to as the acquisition and mastery of what is already known, the extension and clarification of meaning of one's experience and an organized, intentional process of testing ideas essential to problems. Therefore, learning is used to describe a product, a process, or a function.

A paradigm shift is occurring, and millennial students are having different experiences towards teaching and learning. A new generation of learners known as the millennials, born within the years 1982-2004, has immersed themselves in the classroom setting. Being knowledgeable in the experiences of the millennial nursing students is important as we recognize a model of teaching and learning and honor an experience of a student-centered philosophy (Howe, Strauss \& Matson, 2000).
An American author, Norton Juster, once said that "It's just not learning that's important. It's learning what to do with what you learn and learning why you learn that matters". The experience of the millennial students consists of learning why they learn based on perception, views and reason.

The core content of this study is about exploring the teaching and learning experiences of millennial nursing students. This study, in hopes of a valuable result, is essential in exploring the millennial experience in their education. The researchers became aware of the experiences of millennial nursing students with regards to teaching and learning. The researchers looked deeper into how millennial nursing students think-how they experienced teaching and learning in both classroom and clinical area settings; how instructors transmitted knowledge towards their formidable recipients and how these recipients responded to given stimuli. 


\section{Objectives}

This study aims to explore the teaching and learning experience of millennial nursing students.

\section{Scope and Limitation of the Study}

The study was limited to gathering the teaching and learning experiences of the millennial nursing students in Cebu City. A total of eleven (11) key informants were interviewed, all of which were level IV students. The eleven key informants came from three (3) different nursing schools, namely: Cebu Doctors' UniversityCollege of Nursing, Cebu Institute of TechnologyUniversity College of Nursing, and University of San Jose-Recoletos-College of Nursing, where the point of saturation occurred.

\section{Definition of terms}

Millennials: A person reaching young adulthood in the $21^{\text {st }}$ century, born by the years 1982-2004.

Learning Experience: The experience where learning takes place specifically refers to how the recipients of knowledge receive and respond accordingly to the information conveyed by the instructor.

Teaching Experience: The experience of the recipients of knowledge regarding the methods in information transmission is conducted by the instructors to elicit a cognitive response effectively.

\section{RESEARCH METHODOLOGY}

\section{Research Design}

The study utilized a qualitative research design particularly the Husserlian's Phenomenology. Phenomenology, according to Mastin (2017), is the study of experience of sensory perception, action, volition, thoughts, feelings and perception in a particular period of events or phenomena. The core component of this design is the exhaustive experiences of the millennial nursing students concerning teaching and learning.

\section{Research Locale}

The research was conducted in three (3) distinct universities located in Cebu City, Cebu, Philippines namely: Cebu Doctor's University (CDU), Cebu Institute of Technology University (CIT-U), and University of San Jose-Recoletos (USJ-R). These universities offer Bachelor of Science in Nursing (BSN) Degree programs (Schools Offering Nursing) appropriate for conducting the study.

\section{Research Instrument}

The study utilized an in-depth, semi-structured interview for the data collection of the teachinglearning experiences of the millennial nursing students. A semi-structured interview predisposes the researchers to formulate a specific number of focused queries - lesser than the number of questions thrown in structured interviews and more questions than in nonstructured interviews (Doyle, 2018). This intentionally leads to descriptive responses that provide an opportunity for the interviewer to probe deeper into the responses of the key informants. An in-depth interview is a method consisting of open-ended questions which edifies accuracy of the results through eliciting a comprehensive perspective in client's responses (Boyce \& Neale, 2006). The researchers formulated an interview guide which focused on the following concepts: (a) The experiences towards the teaching strategies of the professors in the college of nursing, and (b) the experiences towards facilitation of learning. Using these methods, the researchers were able to explore the learning phenomena of a nursing student.

\section{Sampling Technique}

The researchers have utilized non-probability purposive sampling. This refers to the non-randomized selection of participants to gain information and generate a description of the entire population (Palinkas et al., 2016). The advantage of this type of sampling is that it is efficient and cost-effective procedure appropriate for the study's intentional nature of selecting millennial nursing students.

The study's inclusion criteria determined the qualification of the expected participants. This included nursing students in the level IV, currently enrolled in the Bachelor of Science in Nursing (BSN) programme in any prestigious nursing school in Cebu City, regardless of gender. The participants were physically, emotionally, and psychologically well without the presence of any physical and cognitive disability, as the results were deemed to be accurate and properly conveyed by the informants.

Having chosen qualified key informants, the researchers then presented an informed consent, a written legal paper which contains roles of both the researcher and informants (Kaiser, 2010). Each of the 
key informants accepted the terms and conditions.

\section{Data Gathering Procedure}

The data gathering commenced after the proposal was presented to and approved by qualified panelists, judges and the college dean. Colleges of Nursing in different local universities were informed of the purpose of the study, simultaneously, a transmittal letter was sent to the respective deans. It contained a statement of request to conduct the study within the premises of their university and utility of the students per school.

After the permission was granted and terms were agreed, the researchers then immersed in the actual research locales. The researchers introduced the purpose of the research personally to the key informant, an individual who is socially knowledgeable of the community they are situated in (Payne \& Payne, 2004), and in this study, the college deans were referred to as such.

Based on the qualitative nature of the study, data saturation was used to determine the sample size. Data saturation refers to the satisfaction due to the repetitive establishment of the data acquired from the informants (Walker, 2012). The study was deemed saturated after eleven (11) key informants established repetition of responses.

Specifically, each researcher was delegated with a specific function. These functions were interviewer, audio recorder, and note-taker, while the functions such as data transcriber and data interpreter roles were shared among the researchers to assure transparency and similarity of interpretation.

Specifically, the researcher, assigned as the interviewer, conducted and managed the topics in an appropriate pace. The researcher also managed the interpretation of data through the information gathered in the audio recording and note-taking. The researcher assigned as the audio recorder recorded the conversation via cellular phone and kept it confidential until the data was encoded to the computer and safe-locked in an online database. The researcher assigned as the note-taker was able to take down key concepts verbalized by the key informant, verbatim, and gestures. These were essential in the integration of experience and meaning. Accordingly, each of the three researchers was assigned into a distinct school in transcribing the audio recording. The recordings and notes taken were kept into an online database and confidentiality of results was maintained by securing them in a password-locked database.

The conversation was then encoded and encrypted into the computer and kept confidential through uploading to a password-guarded online document keeper. After a month of data analysis, the researchers contacted the specific informants and revalidated the data collected through electronic messaging. Consequently, each phase of the data gathering process progressed with the rest of the specified research locales.

\section{Data Analysis}

After the data was collected through interview, the researchers proceeded to analyze the data. The researchers used Colaizzi's method as strategy for data analysis. This phenomenological strategy in data analysis is comprised of seven (7) phases, namely (a) Transcription of Informant's Statements, defined as the process of encoding the responses of the informants into the electronic database, (b) Extraction of Significant statements to highlight and formulate information based on the phenomenon studied, (c) Creation of formulated meanings, wherein the researcher attempts to integrate one's meaning into the statements, (d) Aggregation into Theme Clusters, the phase where the statements and thoughts are likened and grouped in similar thoughts, (e) Integrating into Exhaustive Description of the Phenomenon, wherein the researchers will create an exhaustive description for further analysis, (f) Generating Fundamental Structures or phenomenal structure with similar meanings and thoughts and lastly (g) Validation of Exhaustive Description and its Fundamental Structure. This included a follow-up meeting with the key informants for data verification, increasing the credibility and accuracy of results (Procedures of Colaizzi). These were then actualized to guide the researchers into obtaining information on millennial learners.

Initially, the verbatims were transcribed into a codeprotected online database and was surely kept private and confidential. The verbatim were then translated into their corresponding English translations, which were then back-translated to ensure the content was unaltered and was kept in its original syntax. After which, the translated verbatim was treated by extracting significant statements that relates to the objective of the study. Subthemes were then clustered into major themes which categorically provide a widened view of the 
experiences of the informants. Consequently, themes were then treated by formulating meanings which involves digging deeper into the phenomenon to locate the emphasized meaning of that certain phenomenon. The data were then generated into fundamental structures that build the logic and generalized meaning behind the exhaustive descriptions of the informants. After the constructing the experience via Collaizi's method, the researchers then validated the truthfulness and accuracy of the results to the informants via electronic mail and messages.

\section{Rigors of the Study}

The rigors of the study pertain to guarantee the reliability and validity of the process of the study (Krefting, 1991). Prior to the conduct of the actual study, the informants underwent a pilot testing, which is an interview simulation, or a pre-study trial conducted to a sample population not part or lesser than the actual study sample (Second Language Testing INC, 2019). This is to ensure that the questions will most accurately elicit an expected response and eradicate unnecessary queries simultaneously. The research study utilized audio recording and taking note of essential points out from the informant's responses. The whole interview was then transcribed and treated with Colaizzi's method of data analysis. Coding was made possible by a computer programme where significant statements were extracted. A systematic coding structure was necessary to form an organized phenomenological study. All these procedures were recorded and documented, certifying veracity and accuracy of the findings.

\section{Ethical Considerations}

The study considered ethical principles that are necessary to the conduct of the study. Prior to the implementation of the study; the researchers provided written consents that included the scope and purpose of the study, the role of the researchers, the role of the informants, and confidentiality measures. These significantly protect the informant's rights and reduce risk for mental or physical harm. Confidentiality measures were invoked with regards to the results, answers, and responses of the informants towards the given questions. Any break in confidentiality will be traced to the researcher. The informant's identity was kept safe and was not be used for external purposes. This is implemented to protect the client from untoward miscellaneous motives.

\section{RESULTS}

The study was able to extract a hundred and twenty (120) significant statements with forty (40) formulated meanings. Six (6) major themes emerged consequently from the extracted statements specifically:(1) Experiences on the Demands on Efficiency, (2) Experiences on Techno-dependency, (3) Experiences on Interactive Learning, (4) Experiences on TeacherCentric Approaches, (5) Experiences on Learning Styles and (6) Experiences on Teacher Encounters. Each theme was discussed explicitly to further direct clarification and comprehension.

Significant results were yielded from 11 millennial nursing students. Moreover, the informants were selected by means of the eligibility criteria, taking up BSN Programs in 3 distinguished universities in Cebu offering the said bachelor's degree: Cebu Doctors' University, Cebu Institute of Technology-University and University of San Jose- Recoletos. The data gathered satisfactory results as it reached saturation point.

\section{Theme 1: "The Ticks of Time" Experiences on the Demands for Efficiency}

In life, there are times when it's easy but there are also times when roads get rough. This theme emphasizes the need of students to become efficient individuals to be able to manage academic responsibilities. The first major theme has two (2) subthemes, namely: (1.1) "Time Management" and (1.2) "Pressure". Any job worth doing requires great effort and time, and along with this is the physical and mental stress to finish the tasks at hand. One prevealent cause of stress verbalized by the key informants is that they lack time in complying with deadlines. Time allotted for one task is not enough, so they find ways to squeeze in what should be done. Often, a student nurse goes through these day by day, trying to accomplish requirements and pass exams. The students then create strategies to effectively cope and become efficient learners.

Informant 7 shared:

"Para nako akong difficulties kay time. Kulang kayo kosa time. Like karon, nay mga time naigive up nimoang isaka subject kay mas prioritized ni nimo siya ang usa ka subject nya akong style kay mamawi ko sa asa ko gagmayg grado." (For me, one of my difficulties is the lack of time. Now, there are subjects that you would have to give up because this other 
subject is of higher priority and my style is to improve my grades in subjects where I am poorly performing in). $-(\mathrm{SS} 73)$

\section{Informant 4 also related:}

"Ako kay stressful and also challenging kay ako sad daghan sad kog responsibilities labi na officers". (For me, it is stressful and challenging because I have responsibilities as an officer. I really have to manage my time). "Kay their reason for us kay kanang they want us to be more hardworking, kanang para time management sad" (They want us to be more hardworking and to have time management). - (SS3 and SS35).

In an online article, it was said that a millennial's world is flipped upside down when they entered college, because their highschool days were more structured and time-bounded with the guidance of highschool advisers and teachers (Weller, 2017). However, the informants created a way to compensate for the time restriction; compromise is the answer for them. They weigh which one is more important and do that task first. Effective time management for them is finishing tasks at hand in a schedule they see as the most beneficial to them.

\section{Informant 9 said:}

"Luoy lang gyud ang uban nga student nga di gani ka take, kay lain lain biya'g coping ang mga tawo." (It's just that those who can't take the pressure are really burdened, because we have different ways of coping).(SS105). Pressure from the demands of the instructors is seen to have a negative effect on the classmates of the informants. One factor of this type of pressure is that the previous generations seem to have achieved so much in their time and became as a standard for the millennials to follow (Curtin, 2016). The informants claimed that there are those who cannot cope and are consumed by the stressors. The informants see this as a challenge to do better and comply with the requirements.

\section{Theme 2: "The Art of the Advanced" Experiences on the Use of Technology}

Technology has paved its way in influencing the lives of the people especially the millennial cohorts with the rise of social media and electronic search engines. Millennial students have greatly used technology and have been dependent on acquiring information via internet sources and gadgets. The second major theme has three (3) subthemes, which are: (2.1) "PowerPoint Presentations", (2.2) "Online Resources" and (2.3) "Note-Snap". The focus of this major theme is how millennials utilize technology and the internet in the pursuit of acquiring information and education.

A major trend in instruction nowadays is that professors use a software-based platform of creating presentations called PowerPoint, developed by the Microsoft Office Suites. Subsequently, millennial nursing students have been accustomed with lectures delivered through this medium. These lectures are delivered through monitors or visual projections where the lectures are arranged through a slideshow. However, sentiments arise as to how instructors from non-millennial generations impart their lessons through PowerPoint presentations.

Informant 9 testified:

"Sa ilang pag discuss, mubasa ra bitaw silag PowerPoint. Wala gyud mi makat-onan." (On the way they discuss, some would utilize plain reading of Power Point slides. There is no learning at all). - (SS79)

Informant 10 supported with,

"Like kung unsa ray naa sa PowerPoint mao ra sad na siya, so dili sad siya like elaborated pa more, ingana. So, bati siya nga style." (What's in the PowerPoint is not more elaborated. So it's not a good style). $-($ SS89).

The informants assert that it is important that the instructors go beyond the slides. The concept of PowerPoint is that these presentations should be short but comprehensive (Power Point Tips, 2017). For the informants, this may hinder elaboration of the topic if the instructors do not initiate further explanations themselves. Plain reading of the text seems to be less beneficial when compared to extensive lectures.

Online resources created a better medium of sharing information not just for millennials, but for everyone else who has access to it. For millennials, there is no such thing as "too much information". The internet opens new doors for learning which may not be accessible locally. This creates wide options for millennials to choose what information to use and how to use the information gathered.

Informant 3 related that:

"Higher year's notes, friend's notes, online like YouTube videos." (I use higher year's notes, friend's notes, and online resources such as YouTube videos).(SS20) 
Informant 2 also shared:

"Mu watch kog video but usually mag group session mi then nay isa nya murag siyay mu demonstrate sa procedures kay angsa online man gud kay lahiang style nilasailangpag demonstrate." (I watch video but usually, we have a group session then one would demonstrate the procedures because what's on the online is different). - (SS24)

Informant 4 supported with:

"Ako kay books and higher year's notes." (For me books and higher year's notes). - (SS21)

Aside from using online resources, informants expressed their experience in not having to write down notes, but have lectures photographed and saved in their mobile phones instead. Most millennials have relied on the internet and social media to gather information, but it is still evident in the current times that students still use the traditional way of acquiring information, so long as the material aids the student in the learning process.

Informant 4 disclosed that:

"Bawal mag picture, dapat mag notes jud mi tanan pero naa say mag ninja." (Taking pictures is not allowed and we should take notes but there are some who would still snap pictures). $-(\mathrm{SS} 23)$

The informants revealed that even if instructors restrict them from snapping pictures of presentations and lectures, they still do so because it is more convenient than traditional note-taking. An online writer presented that taking pictures of notes are not lazy; it is smart (Watson, 2013). It proves to show that millennials are adaptive enough to use the privilege of technology to aid them in their work.

\section{Theme 3: "The Pampered Pupil" Experiences in the Conduct of Student-Centered Activities}

Pedagogy refers to the provision of methods that caters the needs of students (Callens et al., 2000). When students' learning necessities are placed in front line, the instructor has the advantage in determining topics that need to be discussed, what topics to deliver, and what needs to be elaborated further and congruently reinforced. With this, academic performance may be properly evaluated - taking note of the students' weak and strong points and ensuring that learning is facilitated in the most appropriate method possible. "The Pampered Pupil" paved its way to creating three subthemes namely: Reporting, Group Discussion, and Teacher Supervision.

One way of interacting with students is by assigning them with activities that require delivery of information. From time to time, students are tasked to deliver and discuss topics to their peers. Reporting, or the act of delivering assigned topics to colleagues, is currently implemented in different universities in the purpose of independence, individualistic concept construction, and enhancing interpersonal relationships (Havard School of Public Health, 2018). Although some students are able to adapt to this method of instruction, some informants shared some of its inadequacies and disadvantages.

Informant 7 said:

"Reporting ilang way of discussing mostly. Okay raman nako pero ang problema sa reporting kay akong topic ray akong mafocus, ang mga topics na di akoa kay di sad nako matarong ug tuon." (Reporting is their way of discussing mostly. I'm okay with that but the problem about reporting is that I would only focus on my topic. I can't focus on studying topics that aren't mine).-(SS44).

Informant 4 also stated that,

"For me kay also kanang reporting. It's not kuan man gud. Dili judkanang the way students report. Some students nay ubanmaayu mu report then some students don't explain that much, so as a listener kay kanang di sad kaayu mi muragmakasabot."(I also dislike reporting. Some students report well then there are some who don't explain much. As a listener, we cannot understand). - (SS11).

With these statements, it can be inferred that class reporting poses a learning barrier for the audience - not only does it not effectively transmit the expected learning outcomes from the reporter to the peers, but also, the in-depth comprehension of the topic is made bias to the reporter alone. This results to varied mastery of competencies that would end in non-unified learning. Millennials have already been exposed to the ease of social interaction - $a$ feature that is gained through internet and social media adherence. This millennial feature is being progressively integrated into the student's personality and consequently affects the preferences of students with regards to the methods of instructors in the relay of significant information geared 
towards behavior modification. With this, it is highly essential that students be able to connect with the people around them especially their instructors and colleagues (Dede, 2004). Interactive learning happens during group discussions in which it facilitates opportunities for students to discuss their ideas and opinions and compare their thoughts with their peers. For most students, they view group discussions as avenues for brainstorming, sharing of views and opinions, and learning about their colleague's personalities.

Informant 2 said that,

"Nya para mainternalize jud nako sya, I try to discuss what I learn sa uban. As I discuss man gud kay murag nag process akong mind. Mas dali nako sya ma remember and masabtan if I discuss nako akong nakatunan". (And to internalize it, I discuss what I learn to others. As I discuss, my mind processes and it is easier for me to remember and understand if I discuss what I learn). - (SS17).

Teacher Supervision and frequent guidance is a huge factor in sustaining valuable student-teacher interaction. This emphasizes the concern of instructors towards student's learning and it aims in improving competency of students (Glanz, Shulman \& Sullivan, 2007). It improves the student's perspective on their degree of reliance to instructors, that these teachers will fully maximize their potentials as recipients of knowledge into becoming a knowledge-equipped individual. Consistent supervision, constant follow-ups and conducting learning evaluations are keys to enabling learning.

Informant 8 related that,

"Diri sa amo school, it's nice to know na to have teachers who would prepare us and would give us everything we need. Half of that they would test us with the things they gave us. So we're more ready for tests and exams. After mi mu present sa among presentation they would also present balik like they would just run through what we presented. They make sure we understood the topic." (Here in our school, it's nice to know that you have teachers who would prepare us and give us everything we need. Half of that they would test us with the things they gave us. So we're more ready for tests and exams. After our presentation, they would present the topic again like they would just run through what we presented. They make sure we understood the topic).-(SS59)

Furthermore, nursing students are usually required to make requirements for continuous learning be implemented outside the academe. Written requirements are indispensable in nursing, may it be in lecture, assignments, or clinical rotations. Through giving requirements, instructors can give their feedback based on the performance and knowledge acquired by students directly(Terada, 2015). However, this method of supervision brings negative feedbacks from the students themselves.

Informant 4 shared that,

"Worksheets. We have worksheets and we have four systems. Like karon we have four system ngakailangan I take. In every system there are five diseases and for five diseases kay we need to make five NCPs for each." (Worksheets. We have worksheets and we have four systems. Also, in every system, there are five diseases and for five diseases, we need to make five NCPs for each). - (SS25)

Teacher Supervision also takes place during pre-test and post-tests. This type of evaluative examinations determines the student's degree of accomplishment pertaining to the topic discussed. This form of test taking provides a parameter of learning difference - knowledge prior (pretest) and knowledge after discussion (posttest) (Salkind, 2010). This simultaneously provides baseline information regarding which concepts require further amplification. Also, it helps the instructor to identify the students who are poorly performing and give measures to solve the learning deficiency.

Informant 2 said that:

"Pero usually jud among standard pretest post-test jud na. "(But, usually our standard is pretest and post-test). $-(\mathrm{SS} 27)$

Informant 7 stated that:

"Nindot raman sad diri sa college kay spoonfeeding ba. Combination siya ba kay ang teacher ang magtudlo first nya after ako na dayon ang magtuon about sa iyang gitudlo." (I like it here because they spoon-feed. It's a combination, because the teacher discusses the topic first then afterward I'll study about what he/she discussed). - (SS43) 


\section{Theme 4: "The Paternalistic Professor" Experiences in Encountering Teacher-Centered Activities}

Teaching and learning is a cause and effect relationship. Oftentimes teacher is the root cause of learning and the students' knowledge is the effect of teaching. In teachercentric approaches, the teacher mainly discusses the topic and the students are expected plainly listen and absorb. In other terms, there is minimal student participation (Concordia University Portland, 2012). With this kind of relationship, two subthemes emerged accordingly: Lecture and Autocratic Instructions.

Lecture is a strategy where information is readily provided by the instructors through mere discussion. This is a process wherein information is solely delivered from the instructors to the students. This is further characterized by minimal student participation, where the student is expected to listen to what the instructor has to say(Bajak, 2014). Still endured by some millennials, some suggest that instructors should try new methods in teaching other than simply talking out front.

Informant 3 stated:

"Ang new man gud magkuha silag information from different books then I breakdown nila ang information ila isagoltanan. As they discuss, maghatag silag gamayng example." (On the other hand, the new CIs get information from different books then they breakdown the information and combine everything. As they discuss, they provide examples.) - (SS30)

Informant 6 said:

"Kasagaran bitaw sa amo school na teaching strategy kay spoon-feeding. Kung lecture kay tanan idiscuss, perodependesa teachers kay nay ubanna mu-allow ug reporting. Mudiscuss sila after sa amo reporting”. (Most of the teaching strategies used here in our school are "spoon-feeding". In lectures, everything is discussed, but this would depend on the teachers, because there are some who would allow reporting. They discuss after our reporting). - (SS39)

Autocratic Instructions is considered a teacher-centric approach because the instructions are given by instructors alone and students are obliged to comply without questions (Autocratic Approach to Classroom Management, 2017). This is similar to authoritarian parenting, wherein the parent exclusively decides what actions to take and dictates the child without giving the child an opportunity to beg for reason. This is not welltolerated by the informants as this often leads to poor performances of activities.

Informant 7 shared:

"Magchangeilang instructions kalit regarding something, dilisila consistent sailang instructions. Like nay iingon, nyaipausabnasad, nyamucommentdayunsilag "nganokani man? Di nimao wrong ni." Aside from miscommunication, less ang instructions, dili complete ilang instructions ihatag. So maonamagbalik-baliknapudangestudyantesa tasks. Like sa research, papirmakag letter ikaw pay kasaban samaestra. Kanang nay activities, usarakaana *snaps fingers* change natanan, dili silamusticksa plan ba. Naapuy time naplanadona, nyagichangedayun. Dili silamusticksa plan ba. Like kanisiya kay naa nay plan, nya mu-anadayunangusana ay ganitonalang, superiority complex ba." (Their instructions change abruptly regarding something, and they are not consistent with their instructions. Like they would say this, then it would be changed. Then they would remark "Why is this like this? This is not right. This is wrong". Aside from miscommunication, the instructions are less and the information given is incomplete. As a result, the students would keep on restarting tasks. In activities, just *snaps fingers* then everything is changed, they don't stick to what's planned. There are times that the plan is already constructed, and then it would be changed abruptly. They don't stick to what's been planned. So, there's this student who already has a plan, then comes this CI who says " $\mathrm{Ah}$, let's do this instead"- an example superiority complex). (SS48)

Informant 10 also said:

"Kanangkuan, in addition ra sad sailahakanang they give instructions on the day rabitaw, nyaanguban kay dilijudbiya mi magkuyogtanan, nay ubanngadilikahibalo, nyadilijud disseminated ang information." (In addition to what they said, they give instructions on the day, and we classmates are not together all the time, there are others who are unaware of the announcements, and the information is not properly disseminated). - (SS93)

\section{Theme 5: "The Stylish Schooler" Experiences in Approaches Catering to Different Learning Styles}

In "The Stylish Schooler", the students are determined as to what they prefer most in addressing their needs in learning. Learning is catered through different styles depending on the student's learning style. This 
presented three subthemes namely: Visual Learning, Auditory Learning, and Kinesthetic Learning.

Visual Learners are those who learn through seeing things (Fleming \& Roell, 2018). They remember best from materials they have seen; utilize a visual aid when studying, like a colourful outline of test materials. For this type of learner, visual tools develop the capacity to remember information more completely. Detailed notes are far more important rather than getting involved in discussions for these learners, as well as sitting in the front to create a more detailed gist of what is written. Lastly, they greatly see clear details from illustrations, presentations, and those with spectrum of colours. A visual learner learns best through reading, seeing things and creating a photographic memory.

Informant 4 shared:

"Ako kay mu read ko then ako jud I underline. Kung unsa akong I underline kay murag mao jud ako memorizon dapat ma understand." (I read then underline. Then, I memorize what I underline, and I should understand it). - (SS14)

Informant 10 said:

"Nya millennial biya ta. Daghan biyag mga bag-o karun nya ти prefer biya ta di ти read kay kapoy biya." (We're millennials, there are a lot of new things now. We prefer not to read because it's tiring for us). (SS112)

Auditory learners are those who learn best through hearing things (Fleming \& Roell, 2018). They can benefit from recording lectures and watching videos. Auditory learners are good at writing lectures they've heard. They are also good at oral exams and in study groups. "I'm wanting you to listen" is often the words we hear from these kinds of learners. Humming and talking are amongst the activities that help them retain information. Discussions, talking things through and listening to others are essential in their daily basis of learning. This kind of learner stores information like catch-basins catching every ounce of rainwater, hence they can comprehend to every word fashioned as how they have been heard.

Informant 8 shared:

"Ilisten and pay attention to the discussion. So when its time to study, It's more like of a review nalang. "(I listen and pay attention to the discussion. So when it's time to study, it's more like of a review). - (SS15)
Informant 9 said:

"Mas ma retain sad nako if madungog nako kay makaingun ko nga Ay kahinumdom ko iya ni giingun, kaysa magbasa ra, mag memorize. Pero lahi biya kung mag cramming ka, for example, naka memorize ko ani, pero after sa exam kay mawala biya jud. Murag kato siya kay para lang jud sa kato na exam." (I can retain information better when I say, "I remember that he said this," rather than reading or memorizing. But cramming is different, because after the exam, the information is lost. All that was just for the exam only). - (SS101)

This type of learning shows enhancement of learning when in motion and through experience. Kinesthetic learners are those who learn through experiencing or doing things (Fleming \& Roell, 2018). Kinesthetic learners can benefit from role playing and studying with others. Demonstration is also essential for this type of learner through enhancing of skills. Gestures are the trademark that we often see from these learners. They may need a lot of breaks wanting to move around and may have difficulty retaining what they have seen and have heard. But for these learners, how things have been done imprints more value rather than seeing how things are done and listening to how things are being done, hence having a first-hand manipulation of the objects around to act out their own way to learning. This is commonly referred to as "Experiential Learning" as learning is brought about by performing the actual activity.

Informant 2 said:

"Mu watch kog video but usually mag group session mi then nay isanyamuragsiyay mu demonstrate sa procedures kay angsa online man gud kay lahiang style nilasailangpag demonstrate." (I watch video but usually, we have a group session then one would demonstrate the procedures because what's on the online is different. That's why we discuss first on how to do the procedure then one would demonstrate). (SS24)

Informant 8 stated:

"I'm a kinesthetic learner, so more on hands-on type of learner like during retdemsdihajudmasudtanan that's why ganahankos area kay this is where I learn." (I'm a kinesthetic learner, so I'm more of a hands-on type of learner. I'm able to learn more during return 
demonstrations, that's why I like duties in the clinical area because this is where I learn). - (SS76)

\section{Theme 6: "The Encounters with the Educator" Experiences on the Different Attitudes of Teachers}

This theme describes the connection between the teacher and the students which can greatly affect learning of students and the performance of teachers. Two subthemes surfaced out of this relationship, namely: Positive Encounters and Negative Encounters. Positive encounters have positive implications for both students' academic and social development. Those students who have close, positive and supportive relationships with their teachers will attain higher levels of achievement than those students with more conflict in their relationships (Rimm-Kaufman \& Sandilos, 2017). Relationships based on positive encounters often more give a memorable impact on students having to find a guiding light in the dark alley of struggles faced in their educational endeavour. This encounter pushes the learners to achieve a higher step in the educational ladder knowing that the guiding foundation of their learning was anchored by the core values grounded by the educators. The student-teacher relationship has created positive encounters between the students and teachers in terms of interacting, imparting knowledge and guiding the students in facilitating learning. The students are more likely to be respectful when teachers respect them.

Informant 7 said:

"Nice pudba kay muvalue silag attitude diri, like mudawatrasilag mistakes as long as maka see silana willing muchangeangkanangstudyanteha, or eager siyamakat-on. Muhatagsilag chance. Priority nilaang attitude rather than knowledge. Naayubang instructors na mu-adjust sa students. Naapuy time naang student ang mu-adjust." (It's nice to know that they value the student's attitude here, like they accept mistake as long as they see that the student is willing to change or is eager to change. They give chances. Their priority is attitude rather than knowledge. There are some instructors who would adjust to their students. There are times that the student will be the one to adjust). (SS72)

Informant 2 shared:

"Happy rasadsiguroko for example nay problemana happy raman sad ko kay at least baang CIs karon unlike before kuan man gudsila, dilijudnimosila ma approach dayunperonaay certain changes as we, as years pass by ba. The more sila mas approachable nasila. Dili nasilaanangkuangyudkanang way nga mag instill silag fear sa students kay para ang students mu follow nila." (I'm happy because the CIs before are not approachable and as the years pass by, there are changes. They are more approachable now. They don't anymore instill fear to the students for them to follow). - (SS32)

Negative encounters show teacher-student communications that appear as sarcastic or impolite. Teachers might display their negativity through snide and sarcastic comments toward the student or describe the feeling that they are always struggling or in conflict with a student (Rimm-Kaufman \& Sandilos, 2017). They are negative experiences by students with their teachers. Not being able to approach their educators, the learners may be found lost in the middle or often find themselves gravitating away from their educators finding it more difficult to learn. Rapport, an essential value in teaching-learning is often not being survived all throughout due to the boundaries set by the educators, most often due to personal values that should not have been brought to the professional setting. Hence, narrowing the learners struggle down to a more difficult road where a positive aid should be essential.

Informant 8 said:

"Naajuyubang CI nadili professional sa studentteacher relationship. Makaaffectsa learning namobasta unprofessional ang CI." (There are CI's who are not professional when it comes to studentteacher relationship. It really affects learning if the $\mathrm{CI}$ is unprofessional. There should be a line, a boundary between a student and a CI). - (SS64)

Informant 7 stated:

"Ang other 50\% kay negative kay mutake advantage angmga nursing students, like "si ma'am rabitawna" and they will expect "ah sayonra kayo na, di mana siyahigpit, di mana siyamangextension." (I can say that we are spoiled here in our college. The other $50 \%$ is negative because the nursing students would take advantage like "It's just Ma'am X" and they will expect this would come easy, "she's not that strict, I know she would not give extensions).-(SS75) 


\section{DISCUSSION}

Stress is characterized by emotional or physical tension. More often than not, a student nurse goes through these day by day, trying to accomplish requirements and pass exams. Stress becomes the tail of every nursing endeavour, and as learned through lecture and research, stress must be addressed in order to go on normally in life (Chamberlain College of Nursing, 2014). The unique individuality of a person supports the thought that there are various ways to cope for a problem; unfortunately the efforts of others are not enough to resolve their difficulties in the case of some millennials. The informants, pinpointing time management, also stressed out that the instructors want them perform better regardless of the constraint. The informants related that because of time constraint, they have to give up one thing to make way for another. Subsequently, the informants, created ways on how to cope with their stress in studies. With this, any form of stress should be managed, because how one copes with his problems has a significant effect on their lives. There are various ways that a person can cope with their individual stress; there are those who listen to music, some who do some exercise, or others who play video and board games, among other way (Robinson, Smith, \& Segal, 2019).

Technology plays a major role on the lives of the millennial, with one article stating that without technology, one feels disconnected with friends, and another shared to feel less informed (Nauert, 2010). With this, the millennial nursing student posited that learning is minimal when what the instructors share is just what is being flashed on the screens. Millennial students today are said to be more expressive through digital platforms, for this is their preferred method of acquiring and generating new knowledge (Palfrey \& Gasser, 2010). The informants prefer to have the contents on PowerPoint slides to be discussed thoroughly and be provided with examples that the millennials nursing students could relate to in real-life scenarios.

Online resources for information are the most accessible to millennials, given the advancement of technology. It is said that online resources have made a huge positive impact on the study habits of millennial students (Purcell et al., 2012). The millennial nursing students have incorporated online resources with traditional lecture, note-taking, and books to aid them in their studying. The informants shared that demonstrations from instructors are different from what they find online; thus working out the differences and work within themselves to facilitate learning that they see. With the advent of mobile phones with extensive memory capacities and varying camera applications, the millennials have discovered more advanced way of taking down notes- taking a picture of lectures and PowerPoint presentations (Barkley, 2013). It is in the discretion of the clinical instructor whether or not taking pictures of notes are allowed; but either way, the informants revealed that they prefer this method because it is less hassle when compared to traditional note-taking.

Interactive learning is a pedagogical approach in which students and teachers have lesser boundaries when it comes to learning. It is said that teachers should keep up with the demands of 21 st century students- in ways that promote good interaction between both sides (Ibrahim \& Al-Shara, 2007). Reporting is said to be beneficial in developing the communication skills of students, a learning relevant with the demand of nurses to be excellent health teachers and educators (Bart, 2011). The informants accept reporting as a good way of learning, even with minor cons pointed out. Some informants asserted that they dislike reporting. For them, reporting is not a good way to learn because of some reporters who are not good with reporting. With respect to the reporter, reporting serves as an effective way to hone communication skills. Teachers get feedback from the students and vice versa; and this engagement encourages the opportunity to practice the language of the discipline (Weimer, 2011). The informants claim that there is better retention and understanding of topics when it is discussed thoroughly with peers. Poorly written and constructed paperwork have caused discord in the medical setting (Taran, 2011). Guidance from instructors is needed as it complements learning (Alutu, 2006). The informants expressed elation in knowing that the instructors continue to supervise and guide them in their endeavours. Their evaluation and immediate feedback on students' presentations and examinations support the idea of a well-represented and well-directed learning environment. In the teacher-centric method, the direction of the information is from the instructor to 
the audience (Skills Converged, 2009). The relevance of written requirements is that the student-nurse is competent in verbal communication as documentation is essential in nursing also. The implied gain of taking responsibility of every documentation also extends to developing the patience and perseverance of the millennial nursing student to finish the task at hand. Pre-test and post-test aids learning by determining the weak and strong students, and finding out what the students already know, together with which topic they should study on more (Kuehn, 2017). The informants shared that the pre-test and post-test method of evaluation became a standard for them. This type of collaborative learning assists in the students in knowing that information-sourcing is endless; and that all leads to increased skill and knowledge (Sharma, 2019). The informant sees spoon-feeding of information as positive act of the instructors as it guides them into the right direction on which topics should be studied on. The informants also utilized conventional ways to learn, and even sought help from their seniors on where to get adjuncts for learning. Positive and immediate feedback creates a wholesome relationship between the two and further facilitates learning.

Lecture is a one-way channel of communication of information. Students' involvement in this teaching method is just to listen and sometimes pen down some notes (Farooq, 2012). The informants stressed out that instructors, specifically the new ones, gather information from varied sources and break down the information gathered. The instructors also provide examples to the students. The informants feel that they are being spoon-fed wherein they are provided with everything by their instructors. Information is easily acquired through lecture. Instructors discuss and explain everything to them. The informants feel that their hard work is not given justice just because of sudden changes in instructions. They emphasized that instructions given by the instructors are not given consistently and clearly. This also affects the informants' performance because they become unprepared for such activities due to sudden change of instructions. Efforts of students are disregarded. The instructors give instructions on the day and everybody is not properly informed. Instructions are not properly disseminated to the students. This is unfair for the students because they are unaware of the instructions and they might not be able to carry out the given instructions.

Many people recognize that each person prefers different learning styles and techniques. Learning styles group common ways that people learn. Everyone has a mix of learning styles (Learning- Styles-Online. Com, 2019). Visual learning, often referred to as the spatial learning style, requires that learners first see what they are expected to know (Spanella, 2013). The informants are visual learners and cater learning through reading and memorizing what they have underlined. The informants do not only memorize but makes sure that they understand. The informants do not want to read because it is tiring. There are a lot of things to consider in being a millennial and they do not anymore appreciate traditional method of teaching where students keep on reading. Auditory learner retains information more thoroughly when the information is reinforced through sound (Fleming \& Roell, 2018). The informants prefer to listen to the discussion to retain knowledge, so it is not difficult for them to study. Topics are only reviewed because they have listened to the discussion properly. The informants are auditory learners where they easily remember information through hearing. They prefer listening than reading because in reading, cramming may happen. The informants do not prefer cramming because knowledge only stays for a short time and it is not retained. A kinesthetic learner needs to be actively doing something while learning in order to truly get the materials. Much of the time, they need to get up and move to put something into memory. The informants cater learning through group discussion and demonstration wherein they comprehend by performing procedures. They compare their performance from what they have seen in videos and demonstrate the procedures by themselves. The informants cater learning by being hands-on during return demonstration and duty in the hospital. The informant prefers to perform in actual situations and learn out of it because millennials are known to be experiential rather than theoretical, engaging and interactive (Skiba, 2005).

The communication between the student and the teacher serves as a connection between the two, which provides a better atmosphere for a classroom environment (Jones, 1981). The students will resist rules and procedures along with the consequent 
disciplinary actions if the foundation of a good relationship is lacking (Boynton \& Bonyton, 2005). The informant appreciates that the instructors value the attitude of the students as long as students are willing to change for the sake of learning. The instructors give chances to students. Instructors and students adjust with each other, so that learning is facilitated and they meet half-way. The informants are happy that the instructors are approachable because this may be a way for the problems of the students to be catered and to avoid miscommunication. They are also glad because they are not anymore afraid of the instructors who do not anymore instill fear to them. A lack of awareness on the part of the instructor leads to poor teacher-student relationships (Tucker, 2019). The informant's learning is affected when instructors are unprofessional. Unprofessional refers the taking personal matters within and outside the boundaries of the classroom. This affects learning because the connection between students and teacher is altered. The informant is dismayed by the other students who take for granting the goodness of some instructors in terms of strictness and in giving extensions. The students are spoiled by the instructors and students take advantage because of that.

\section{Exhaustive Description}

Comprehensively, the informants were able to share and highlight varied experiences on how they were taught by their instructors and how they were able to learn accordingly. The informants expressed their feelings inside the millennial-dominated classroom: being governed by different kinds of instructors. The needs of the students may easily be taken unaccounted for and with that, learning may also gradually cease to progress. Therefore, it is important to investigate the psychological impact of teaching in the mind of a millennial nursing student.

Basically every student is required to be efficientefficient in managing responsibilities, obligations and other school-related stressors. Stress according to Chamberlain, College of Nursing (2014) is vital in one's daily life processes and is indeed considered to be beneficial when it comes to accomplishing tasks and goals. The informants related to this premise testify that one of the problems they encounter is time management. This problem is further associated with another stressor which is feelings of being pressured by the professors, brought about by written requirements, school activities, and other instructions that need to be fulfilled in a specific duration of time. With the pressure put on by the instructors, the need to manage one's time arises instinctively and may call for an alteration in one's functioning.

Millennials being techno-savvy and digitally-adept as indicated by Barkley (2013) and Larsen (2006) predisposes them to instantaneous acquisition of information. A student may advertently use personal gadgets into mediums of education. The internet alone is an exhaustive informational habitat where one can learn a specific concept at any place, at any time. During discussions, the students may readily use their mobile cameras to take pictures of contents presented on the board or in PowerPoint slides. Given these privileges, the student supports their classroomacquired knowledge by looking further into the topic through educational websites, PDF's, e-books and educational forums. Power Point presentations also ease the difficulty in discussing topics. The informants testified the use of PowerPoint slides during discussions, where it is considered stimulating to the senses, provides graphic illustrations to support the content, and can be easily passed on by instructors through giving a digital copy to the students thereby easing the workload in note-taking.

Relevantly, due to the successive use of the internet and social media, the millennials are quite known to take social interactions quite as easily (Nicolas \& Lewis, 2008). Certainly, most of the informants attested that interactive discussions must be put to place. Most prefer group discussions, where one is immersed in a group setting, whether formal or informal, and everyone gets to share their ideas and interact actively with one another. Class reportings, wherein a student presents the topic to his/her colleagues, collected both positive and negative testimonies, as the student assigned to report a specific topic can probe into, while other students tasked with other topics does not get an opportunity to do so. In the end, the students have varied competencies and have gained unequal amount of knowledge. The informants also attested the importance of frequent supervisions by the teacher. Specifically, these are situations where the teachers instantaneously provide a feedback regarding the student's performance, through an evaluation such as 
pre-test and posttest, or through revalidating topics via question and answer method.

As much as the millennial nursing students prefer interactive teaching methods, most of them are not in favor with the use of traditional teaching methods such as teacher-dominated discussions and lectures, precisely. The study showed lowered learning interest when it comes to instructors utilizing these methods, as these are monotonous, teacher-centered rather than student-centered learning. According to O'Toole and Welt (1989), nursing is an interpersonal profession, thereby return demonstrations are considered necessary. Unclear, autocratic, teacher-dominated instructions also pose a problem for the students, encountered mostly during hospital/community area duties and some in school activities. They say physical and mental preparations are nullified when instructions are changed abruptly, leading to decreased learning interest and altered situational performances.

Learning styles are acquired developmentally, meaning, they are learned gradually through different academic settings and levels. As a result, each student has a favored technique in which he/she believes to facilitate learning within him/her. Ideally, teaching methods should be coherent with the student's learning styles. This is otherwise observed by the informants. The types of learning styles indicated by the informants were (1) visual learning style, which is learning through reading and memorizing, (2) auditory learning style, identified as retaining information through listening and music stimulation, and (3) kinesthetic/experiential learning style, defined as actively performing instructions as means of retaining information hrough application (Fleming \& Roell, 2018). According to the informants, an initial assessment may be conducted to categorize the learners in the purpose to facilitate learning using appropriate methods catering each learning style.

Millennials value interaction. This is not only applicable to colleagues but also to the higher league which are the college professors in this case. Millennial students have identified specific encounters with professors, both positive and negative. When met with a professor's approachable and accommodating aura, the students can learn more effectively leading to better performance and outcomes as opposed with encountering strict and unapproachable instructors
(Tucker, 2019). Students may want to inquire to reinforce what's learned in the discussion; therefore, having an instructor who presents willingness to accommodate the problems of the student is beneficial to the learning experience of the students.

A learner is identified not on the number of medals and trophies he earned but on how he overcame the challenges brought about by the system. Millennials Magnified presents how millennial nursing students actively engage with situational conflicts and more importantly, how they adjust with these identified conflicts in the $21^{\text {st }}$ century classroom. The experiences -both positive and negative-influenced them on becoming adaptive individuals: learners who are ready to wave the millennial flag in the educational world.

\section{Validation}

The researchers presented the research findings to the key informants and their outlooks on the study were obtained via electronic messages. All key informants confirmed their approval towards the results presented after reading their experiences towards teaching and learning as millennial nursing students.

\section{CONCLUSION}

Learning takes place in the hands of an effective educator. Without efficacy and efficiency, the tendency to foster a high-quality outcome congruently diminishes. The study presented the relationship between learning experiences and technological influence. With technology enhancing relay of information between individuals through social media, millennial students tend to choose group discussions rather than individualized learning. The use of internet predisposes the millennials to engage in utilizing online resources such as ebooks, PDF, online articles and educational websites as they are easily accessed. Additionally, because of the advent of mobile devices, the student may readily take pictures of notes rather than writing them.

The study also presented the relationship of slowpaced, conventional teaching approaches and learning. Despite being tolerated, activities that take up time such as reading books, merely listening to teachercentric lectures, writing and copying notes and doing written requirements showed poor learning enthusiasm as evidenced by negative testimonies asserted by the informants. 
Consequently, the key informants favor a positive student-teacher relationship characterized by constant supervision, provision of instant feedbacks, and display of an accommodating fascade. Moreover, the millennial nursing students prefer instructors who can recognize the reality of students having individualized needs, varied learning styles and that they learn more effectively if congruent approaches are implemented. Furthermore, they want a teacher who could recognize this intellectual diversity and could incorporate this recognition into providing a flexible instructional method that will enable effective learning in the millennia.

With these premises, we can say that a millennial has already processed and accepted the reality of interactivity, self-expression and diversity using social media and internet. This bridges to what are known as millenial learning: interactive than individualistic; experiential rather than theoretical, technologyoriented rather than conventionally-adept.

\section{RECOMMENDATION}

The study rendered data that is significant in the provision of congruent millennial nursing pedagogy. The transcript of teaching and learning experiences may be utilized as a conceptual framework in creating an equivalent and timely nursing education. As for researchers inclined to using qualitative research designs; the study utilized an in-depth semi-structured interview tool. Researchers may use another tool that would assist in gathering significant data that are uncovered within the scope of the study.

\section{REFERENCES}

Alutu, A. N.G. (2006). The Guidance Role of the Instructor in the Teaching and Learning Process. Journal of Instructional Psychology, 33(1).

Bajak, A. (2014). Lectures Aren't Just Boring, They're Ineffective, Too, Study Finds. Retrieved from: http://www.sciencemag.org/news/2014/05/lectures -arent-just-boring-theyre-ineffective-too-studyfinds.

Barkley, G. (2013). Students Use New Methods of Taking Notes in the Classroom. Retrieved from:http://www.sbstatesman.com/2013/03/25/stu dents-use-new-methods-of-taking-notes-in-theclassroom/
Bart, M. (2011). The Five R's of Engaging Millennial Students. Retrieved from: http://www. facultyfocus .com/articles/teaching-and-learning/the-five-rs-ofengaging-millennial-students/

Boyce, C. \& Neale, P. (2006). Conducting In-Depth Interviews: A Guide for Designing and Conducting In-Depth Interviews for Evaluation Input. Retrieved from: http://www2.pathfinder. org/site/ DocServer/m_e_tool_series_indepth_interviews.pdf

Boynton, M. \& Boynton, C. (2005). Educator's Guide to Preventing and Solving Discipline Problems. Retrieved from: http://www.ascd.org/publications/ books/105124.aspx

Callens, P., Branton, B., Gedies, T. \& Goodmurphy, M. (2000). Andragogical and Pedagogical Differences Relative to their Interfacing with Internet Resources. Retrieved from:http://citeseerx.ist.psu.edu/viewdoc/ download;jsessionid=01C4CFA0F5A51DBF1FC00 F0296D0B686?doi=10.1.1.498.9788\&rep=rep1\&ty $\mathrm{pe}=\mathrm{pdf}$

Chamberlain College of Nursing. (2014). 7 Ways to Manage Anxiety While in Nursing School. Retrieved from: https://www.chamberlain.edu/blog/7-waysmanage-anxiety-nursing-school.

Concordia University Portland. (2012). Which is Best: Teacher-Centered or Student-Centered Education? Retrieved from:resources/which-is-best-teachercentered -or-student-centered-education/

Curtin, M. (2016). Why Millennials Should Stop Trying to Be Successful...Immediately. Retrieved from: https://www.inc.com/melanie-curtin/whymillennials-feel-more-pressure-to-succeed-than-anyother-generation.html

Dede, C. (2004). Planning for Neomillennial Learning Stuyles: Implications for Investments in Technology and Faculty. Retrieved from: https: //www. educause .edu/research-and-publications/books/educating-netgeneration/planning-neomillennial-learning-styles -implications-investments-tech

Doyle, A. (2018). What is a Semi-Structured Interview? Retrieved from: https://www.thebalancecareers.com/ what-is-a-semi-structured-interview-2061632

Farooq, U. (2012). Lecture Method of Teaching, Definition, Advantages \& Disadvantages. Retrieved from: www.studylecturenotes.com/social- sciences /education/382-lecture-method-of-teaching-social- 
sciencesdefinition-advantages-a-disadvantages

Fleming, G. \& Roell, K. (2018). The Auditory Learning Style.Retrieved from: www.thoughtco.com/auditory -learning-style-1857081

Glanz, J., Shulman, V. \& Sullivan, S. (2007). Impact of Instructional Supervision on Student Achievement: Can We Make the Connection? Pages 28.

Howe, N. \& Strauss, W. \& Matson, R.J. (2000). Millennials Rising: The Next Great Generation, 3rd Edition, Vintage, USA.

Ibrahim, M. \& Al-Shara, O. (2007). Impact of Interactive Learning on Knowledge Retention. Retrieved from: https:/link.springer.com/chapter/10.1007/978-3-540 -73354-6_38

Jones, V. F. (1981). Responsible Classroom Discipline: Creating Positive Environments and Solving Problems. Allyn \& Bacon, USA.

Kaiser, K. (2010). Protecting Respondent Confidentiality in Qualitative Research. Qualititative Health Research,19(11), pp 1632-1641

Krefting, L. (1991). Rigor in Qualitative Research: The Assessment of Trustworthiness. The American Journal of Occupational Theory. 45(3), pp 214-222

Kuehn, P. (2017). Function and Importance of Pre and Post Tests. Retrieved from: https://owlcation.com/ academia/PrePost-Test-A-Diagnostic-Tool-For More-Effective-Teaching-of-EFL-Students

Larsen, B. (2006). Understanding Generational Differences in Education. Retrieved from: http://www.winona.edu/asf/Media/Generational_ Differences-Larsen.pdf

Learning- Styles-Online.com.(2019). Overview of Learning Styles. Retrieved from: https://www.learning -styles-online.com/overview/

Mastin,L.(2017).PhilosophyBasics.Retrievedfrom:http: //www.philosophybasics.com/branch_ethics.html

Nauert, N. (2010). College Students 'Addicted' to Social Media, Study Finds. Retrieved from: https://www.livescience.com/9888-collegestudents-addicted-social-media-study-finds.html

Nicolas, A. \& Lewis, J. (2008). Millennial Attitudes Toward Books and E-Books. Retrieved from: https://digitalcommons.salve.edu/cgi/viewcontent. cgi? article $=1026 \&$ context $=$ fac_staff_pub
O'Toole, A.W. \& Welt, S.R. (1989). Hildegard E. Peplau, Selected Works Interpersonal Theory in Nursing. Retrieved from: https://link.springer.com/ content/pdf/bfm\%3A978-1-349-13441-0\%2F1.pdf

Palfrey, J. \& Gasser, U. (2010). Born Digital: Understanding the First Generation of Digital Natives. Basic Books, New York.

Palinkas, L., Horwitz, S. Green, C, Wisdom, J., Duan, N. \& Hoagwood, K. (2016). Purposeful Sampling for Qualitative Data Collection and Analysis in Mixed Method Implementation Research. Administration and Policy in Mental Health,42(5), pp 533-544

Payne, G. \& Payne J. (2004). Key Concepts in Social Research. Retrieved from: http ://methods.sagepub .com/book/key-concepts-in-social-research

Purcell, K., Rainie, L ., Heaps, A., Buchanan, J., Friedrich, L., Jacklin, A., Chen, C.\& Zickuhr, K.(2012). How Teens Do Research in the Digital World. Retrieved from: http://www.pewinternet.org/ files/oldmedia/Files/Reports/2012/PIP_Teacher SurveyReportWithMethodology110112.pdf

Rimm- Kaufman, S. \& Sandilos, L. (2012). Improving students' relationships with teachers to Provide essential supports for learning. Retrieved from: $\mathrm{http} / / / \mathrm{www}$.apa.org/education/k12/relationships.as $\mathrm{px}$ ?item $=1 \#$

Robinson, L., Smith, M. \& Segal, R. (2019). Stress Management. Retrieved from: https://www.helpguide .org/articles/stress/stress-management.htm

Salkind, N. J. (2010). Pretest-Posttest Design. Retrieved from: http://methods.sagepub. com/reference /encyc-of-research-design/n331.xml

Second Language Testing INC. (2019). Pilot Testing and Field Testing. Retrieved from: https://www.2lti. $\mathrm{com} /$ test-development/pilot-testing-and-fieldtesting/

Sharma, A. (2019). Designing Learning for Millennials. Retrieved from:https://www.td.org/ Publications/Magazines/TD/TD-Archive/2016/06/ Designing-Learning-for-Millennials

Skiba, D. J. (2005). The Millennials: Have they arrived at your school of nursing? Nursing Education Perspectives, 25(6), pp 370-371. 
Skills Converged. (2009). Effective Teaching Methods: One Way Teaching. Retrieved from: www. skillscon -verged.com. FreeTrainingMaterials/tabid/258/arti cleType/ArticleView/articleId/685/Effective-Teaching -Methods-One-Way-Teaching.aspx

Spanella, T. (2013). Visual Learning Style: Definition \& Characteristics. Retrieved from: study.com/academy/lesson/visual-learning-style-definitioncharacteristics.html

Taran, S. (2011). An Examination of the Factors Contributing to Poor Communication Outside the Physician-Patient Sphere. McGill Journal of Medicine,13(1), pp 86-91.

Terada, Y. (2015). Research Trends: Why Homework Should Be Balanced. Retrieved from: https://www. edutopia.org/blog/research-trends-is-homeworkeffective-youki-terada

Tucker, K. (2019). What are the Causes of a Poor Relationship Between a Student \& Teacher. Retrieved from: classroom.synonym.com/causes- poor-relationship-between-student-teacher20337.html

Walker, J. (2012). The use of saturation in qualitative research. Canadian Journal of Cardiovascular Nursing, 22(2), pp 37-46.

Watson, A. (2013). What's your perspective? How do you teach students to take notes in the 21st century? Retrieved from: https://the corner stone for teachers.com/ why-using-a-camera-to-take-notes-is-smart-not-lazy/

Weimer, M. (2011). 10 Benefits of Getting Students to Participate in Classroom Discussions. Retrieved from: https: //www.facultyfocus.com/articles/teaching - and -learning/10-benefits-of-getting-students-to-participate -in-classroom-discussions/

Weller, C. (2017). Business Insider. 'Don't get me started about the testing': Teachers reveal how education has changed dramatically over the past 20 years. Retrieved from: https://www. businessinsider .com/teachers-how-education-has-changed-2017-5 